\title{
Medievalista
}

Online

$20 \mid 2016$

Número 20

\section{Monstruos, prodigios y maravillas en los viajes de Pero Tafur}

Monsters, prodigies and wonders in Pero Tafur's trips

\section{Pablo Castro Hernández}

\section{(2) OpenEdition \\ Journals}

Edición electrónica

URL: http://journals.openedition.org/medievalista/1202

DOI: 10.4000/medievalista.1202

ISSN: 1646-740X

Editor

Instituto de Estudos Medievais - FCSH-UNL

Referencia electrónica

Pablo Castro Hernández, « Monstruos, prodigios y maravillas en los viajes de Pero Tafur », Medievalista [En línea], 20 | 2016, Publicado el 01 diciembre 2016, consultado el 10 diciembre 2020. URL : http:// journals.openedition.org/medievalista/1202; DOI : https://doi.org/10.4000/medievalista.1202

Mediavalista está licenciado com uma Licença Creative Commons - Atribuição-NãoComercial 4.0 Internacional. 
Revista ISSN 1646-740X

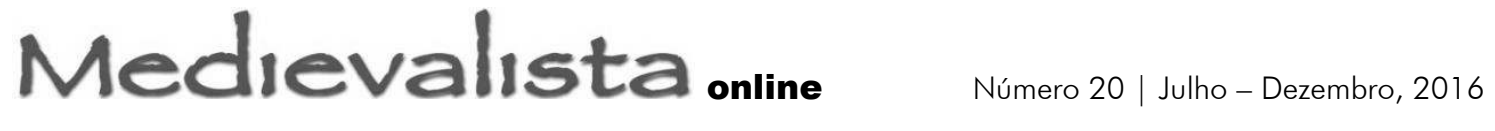

Título / Title: Monstruos, prodigios y maravillas en los viajes de Pero Tafur / Monsters, prodigies and wonders in Pero Tafur's trips

Autor(es) / Author(s): Pablo Castro Hernández

Universidade / University: Pontificia Universidad Católica de Chile / Universidad Alberto

Hurtado / Universidad de los Andes / Universidad Academia de Humanismo Cristiano

Faculdade e Departamento / Unidade de Investigação - Faculty and Department /

Research Center: Instituto de Historia / Bachillerato en Humanidades / Centro de Estudios

Generales / Escuela de Historia

Código Postal / Postcode: $\mathbf{8 3 2 0 0 0 0}$

Cidade / City: Santiago

País / Country: Chile

Email: pfcastro@uc.cl

Fonte: Medievalista [Em linha]. Direc. Bernardo Vasconcelos e Sousa. Lisboa: IEM. Disponível em: http://www2.fcsh.unl.pt/iem/medievalista/MEDIEVALISTA20/hernandez2006.html

ISSN: 1646-740X

Data recepção do artigo / Received for publication: 6 de Abril de 2015

Data aceitação do artigo / Accepted in revised form: 20 de Maio de 2016 


\section{Resumo}

El presente estudio aborda el concepto de lo monstruoso en los libros de viajes a fines de la Edad Media, revisando de manera concreta el caso de las Andanças e viajes de Pero Tafur, un escrito de viajes español redactado durante el siglo XV. Si bien la historiografía reciente sostiene que en la obra de Tafur los eventos sobrenaturales y maravillosos son escasamente utilizados por el viajero, nuestra investigación examina cómo el cuadro de lo monstruoso se inserta dentro de la tradición de las maravillas en los relatos de viajes medievales. El concepto de lo monstruoso refleja un desorden dentro de la naturaleza, dando cuenta de una anormalidad corporal o física, o en las actitudes barbáricas y bestiales de las criaturas. Lo monstruoso representa lo bajo y lo perverso, una anomalía que escapa de las formas tradicionales de la naturaleza y que conlleva a lo excesivo y lo grotesco. En este sentido, Tafur aplica este concepto de lo monstruoso en sus andanzas, conservando el recurso de los mirabilia de la tradición narrativa de los viajeros medievales. Es así como el monstruo se manifiesta a través de seres prodigiosos y bestias salvajes, los cuales dan cuenta del carácter extraordinario y sobrenatural. En otras palabras, el monstruo denota elementos explícitos que marcan una diferencia; pero al mismo tiempo, ese otro, constituye aquello que genera sorpresa, estupefacción, terror y maravilla.

Palavras-chave: Monstruos, Maravillas, Viajes, Pero Tafur, Edad Media 


\section{Abstract}

This paper analyzes the concept of the monstrous in travel books from the late Middle Ages. We review the work Andanças e viajes by Pero Tafur, a Spanish travel book written during the fifteenth century. While the recent historiography argues that the supernatural and wonderful events are scarcely used by the traveler in his work, our research examines how the notion of the monstrous is inserted into the tradition of the wonders of the medieval travel. The monsters reflect a disorder in nature, representing the low and evil. They are an anomaly that escapes from traditional forms, expressing excessive, huge and grotesque characteristics. Tafur applies this concept of the monstrous in his travels and adventures. The traveler preserves the use of mirabilia narrative tradition of medieval travelers. For the traveler, the monster is manifested through prodigious beings and wild beasts, having an extraordinary and supernatural character. In other words, the monster denotes explicit elements that make a difference; but at the same time, creates surprise, amazement, horror and wonder.

Keywords: Monsters, Wonders, Travels, Pero Tafur, Middle Ages 


\section{Monstruos, prodigios y maravillas en los viajes de Pero Tafur / Monsters, prodigies and wonders in Pero Tafur's trips}

Pablo Castro Hernández

\section{Introducción}

El estudio de las maravillas en la sociedad medieval comprende un amplio conjunto de elementos extraordinarios y sobrenaturales, los cuales generan sorpresa y admiración. En cierta medida, los mirabilia se definen como seres, fenómenos u objetos que asombran por su carácter insólito y portentoso. Las maravillas se asocian a fronteras lejanas y espacios completamente desconocidos; es aquello que genera una ruptura con el mundo cotidiano de la sociedad. Sin ir más lejos, en las narraciones de los viajeros medievales notamos el encuentro con elementos naturales y sobrenaturales, estableciendo un constante diálogo entre el hombre y su entorno real y extraordinario. Ya esto se vislumbra concretamente en la percepción de los mirabilia como elementos maravillosos, mágicos, milagrosos, extraños y monstruosos, donde se aceptan estos fenómenos que sorprenden por su naturaleza prodigiosa y diferente. ${ }^{1}$

Cabe mencionar que el presente estudio se centra de forma particular en uno de los elementos del conjunto de las maravillas, esto es, el cuadro de lo monstruoso. En primer lugar, se examina el concepto del monstruo como una anomalía, exceso y diferencia por parte de

\footnotetext{
${ }^{1}$ Para una mayor revisión conceptual de lo maravilloso, véase: CASTRO HERNÁNDEZ, Pablo - "La tradición de las maravillas en las Andanças e viajes de Pero Tafur (1436-1439)". LEMIR, Revista de Literatura Española Medieval y del Renacimiento, n. 18 (2014), pp. 329-382.
}

Medievalista online № 20 | Julho - Dezembro 2016 ( ) IEM - Instituto de Estudos Medievais 4 
criaturas prodigiosas, revisando diversos casos en la narrativa de viajeros de los siglos XIII al XV. Posteriormente, se ahonda en el caso de las Andanças e viajes de Pero Tafur, un libro de viajes español escrito hacia 1454, analizando la aplicación del cuadro de lo monstruoso en su obra.

Hemos considerado principalmente las Andanças e viajes, ${ }^{2}$ puesto que esta obra nos muestra un recorrido del autor por el mundo Mediterráneo, Europa y Oriente, dando cuenta de diferentes elementos culturales en su itinerario. Este relato es escrito hacia 1454, en lo cual se narran las aventuras y viajes del caballero español por el mundo mediterráneo, europeo y oriental. Nos entrega una amplia y riquísima información sobre las andanzas del viajero sevillano por el mundo conocido, describiendo las ciudades, los pueblos, sus costumbres y formas de vida. Asimismo, se refiere a la naturaleza y la fauna que observa en los territorios que recorre. La obra de Tafur pone especial énfasis a elementos políticos, sociales y comerciales, estableciendo valiosas anotaciones de su época y contexto histórico.

Respecto a la relación con el plano de lo maravilloso, la obra de Tafur resulta singular, en cuanto busca narrar sucesos que aludan a fenómenos y elementos extraños y sorprendentes como parte de una tradición de los viajeros medievales. Si bien en algunos casos el autor manifiesta una postura crítica, racional o escéptica frente a diferentes elementos prodigiosos y maravillosos, la mención de estos componentes sobrenaturales y extraordinarios no está ausente en su relato, sino que se encuentran presentes a través de los distintos modos de aplicación del concepto de la maravilla. El mismo viajero reconoce una presencia conceptual de lo sobrenatural y lo asombroso. En otras palabras, el viajero español se apoya en el mismo lenguaje del cuadro de lo maravilloso que utilizan sus antecesores de los siglos XIII y XIV, es decir, para el autor no todo es maravilla en sus descripciones de fenómenos, criaturas y objetos, sino que hay elementos extraordinarios, mágicos, milagrosos, extraños y monstruosos. Es así como Tafur continúa con una tradición de los relatos de viajeros

\footnotetext{
${ }^{2}$ TAFUR, Pero - Andanças e viajes. Ed. Miguel Ángel Pérez Priego. Sevilla: Fundación José Manuel Lara,
} Clásicos Andaluces, 2009. 
Monstruos, prodigios y maravillas en los viajes de Pero Tafur - Pablo Castro Hernández

medievales, aplicando sus mismos recursos narrativos, pero sobre todo, incluyendo componentes sobrenaturales y extraordinarios como parte de su realidad cultural.

Ahora bien, de manera particular con el caso de los mirabilia, algunos autores sostienen que el relato de viajes de Tafur disminuye el uso de los elementos prodigiosos, los cuales según Miguel Ángel Pérez Priego, Rafael Beltrán o Karen Daly dejan de ser sobrenaturales. ${ }^{3}$ En esta misma línea, Ángel Luis Molina expresa que el viajero se muestra escéptico e incrédulo ante este tipo de eventos, desprendiéndose de la responsabilidad de narrar acontecimientos sobrenaturales. ${ }^{4}$ Incluso, tal como plantea Ança Crivat, los elementos maravillosos caen en desuso total en su escrito. ${ }^{5}$ Bajo nuestra perspectiva, el uso de las maravillas no desaparece

\footnotetext{
${ }^{3}$ Miguel Ángel Pérez Priego sostiene que lo maravilloso no existe como tal, sino que el viajero racionaliza las maravillas a elementos más familiares, mostrándose escéptico y reticente frente a los eventos sobrenaturales [PÉREZ PRIEGO, Miguel Ángel - "Estudio literario de los libros de viajes medievales". Revista de Filología, n. 1 (1984), pp. 231-232. El mismo autor señala que Tafur es un viajero pragmático y racionalista, que no deja gran lugar a las maravillas, y cuando las introduce, la propia realidad o los testimonios de otros personajes tratan de desmentir esta relación con lo extraordinario [PÉREZ PRIEGO, Miguel Ángel - "Maravillas en los libros de viajes medievales". Compás de Letras, n. 7 (1995), p. 69]. En esta misma línea, Rafael Beltrán indica que en la obra de Pero Tafur se habla de 'maravillas reales', de obras de la naturaleza o del hombre que impresionan y que parecen increíbles: los animales fantásticos son la jirafa, el elefante, la cebra, el cocodrilo, el hipopótamo, el camello [BELTRÁN, Rafael - "Libro de viajes medievales castellanos. Introducción al panorama crítico actual: ¿cuántos libros de viajes medievales castellanos?". Filología Románica, Anejo I (1991), p. 135]. Según Karen M. Daly, el libro de viajes del caballero español no contiene casi ninguna maravilla extraordinaria y leyenda fabulosa de los relatos de viajes medievales, incluso, apunta a un alejamiento en la mención de criaturas monstruosas referidas por autoridades clásicas. En este sentido, el viajero proporciona una visión global y coherente de lo 'maravilloso real', donde las maravillas presenciadas por él incluyen construcciones hechas por el hombre, objetos lujosos o maravillas que solo impresionan por lo inusual y sorprendente, sin poseer ninguna cualidad fantástica [DALY, Karen M. - "Here there be no dragons: Maravilla in two fifteenth-century spanish libros de viajes". Notandum, vol. XV, n. 29 (2012), p. 27].

${ }^{4}$ Ángel Luis Molina señala que Tafur no era demasiado crédulo, exponiendo sus dudas con expresiones "yo no lo vi" o "dizen", mostrando cierta duda para no cargar con la responsabilidad de lo que narra [MOLINA MOLINA, Ángel Luis - "Pero Tafur, un hidalgo castellano en Tierra Santa y Egipto". Cuadernos de Turismo, n. 27 (2011), p. 643].

${ }^{5}$ CRIVAT-VASILE, Anca - "Mirabilis Oriens: fuentes y transmisión". Revista de Filología Románica, n. 1112 (1994-1995), p. 478. Sofía Carrizo Rueda señala que Tafur solo incluye en su obra algunas tradiciones sobre sucesos milagrosos, y con respecto a las maravillas de la India se limita a reproducir lo que le cuenta el viajero italiano Nicolo de Conti, quien si bien afirma haber conocido al Preste Juan, a las preguntas del viajero español sobre los hombres con un solo pie o un solo ojo responde que él no los vio [CARRIZO RUEDA, Sofía "Símbolos, mitos y prodigios en el horizonte de los viajeros medievales". Quimera, Revista de Literatura, n. 246-247 (2004), p.15]. En una línea similar, Barry Taylor menciona brevemente el caso de las maravillas en los libros de viajes hispánicos. De manera particular, en las andanzas de Tafur destaca el encuentro con Nicolo de Conti, quien le indica que no vio los monstruos a los cuales se refiere Plinio en dichas tierras. El viajero veneciano solo le dice que vio un elefante blanco, un asno multicolor y algunos unicornios. En cierta medida, se apoya en el testimonio de otro viajero, manteniendo una postura imparcial y escéptica frente a las cosas extraordinarias, reduciendo la mención de las maravillas y razas fabulosas tan características de los libros de viajes medievales [TAYLOR, Barry - "Late medieval Spanish travellers in the East: Clavijo, Tafur, Encina and
}

Medievalista online № 20 | Julho - Dezembro 2016 ๑ IEM - Instituto de Estudos Medievais 6 
en la narrativa de viajes de Tafur, por el contrario, el caballero sevillano las menciona mediante eventos extraños, maravillosos y milagrosos en su obra. Particularmente, el cuadro de lo monstruoso muestra una relación con lo sobrenatural, en la medida que los elementos extraordinarios son aceptados como parte de la creación de Dios, como también con lo exótico y lo diferente, en cuanto los seres monstruosos se asocian a criaturas regidas por lo salvaje y lo bestial, alejados de todo sentido de civilización. En este sentido, podemos notar cómo la mención de las maravillas y los monstruos en las andanzas de Tafur, aunque de manera contenida, permiten articular modos narrativos que entregan líneas acerca de la identidad cultural del viajero y su percepción del mundo. El viajero puede reconocerse como alguien distinto a la otredad. Pero al mismo tiempo, la mención de los seres monstruosos en su obra refleja un interés por presentar los prodigios y maravillas de las tierras lejanas, los cuales sorprenden por su naturaleza fabulosa e incentivan la curiosidad y el deseo de conocer el mundo.

\section{II}

\section{Monstruos y prodigios en los libros de viajes medievales}

El encuentro con los monstruos, dentro de la narrativa de los viajes medievales, constituye una relación con la rareza y singularidad de las tierras lejanas. El monstruo refleja una oposición al orden. Simboliza las fuerzas irracionales, como también las características de lo informe, lo caótico, lo tenebroso y lo abisal, apareciendo como lo desordenado y lo desmedido. ${ }^{6}$ Según Claude Kappler, para "el hombre medieval el monstruo es una "anomalía normal", un avatar necesario, inevitable, misterioso", ${ }^{7}$ en cierta medida es una forma que expresa la diferencia. ${ }^{8}$ Lorraine Daston y Katharine Park, ven en los monstruos, prodigios y portentos una desviación del orden natural. ${ }^{9}$ Incluso, tal como agrega Lillian von der Walde Moheno, en los monstruos medievales "se concentran y personifican los deseos y temores

Tarifa". in ALLEN, Rosamund (ed.) - Eastward Bound: Travel and Travellers, 1050-1550. Manchester: Manchester University Press, 2004, pp. 225-226].

${ }^{6}$ CHEVALIER, Jean; GHEERBRANT, Alain - Diccionario de Símbolos. Barcelona: Herder, 1986, p. 721.

${ }^{7}$ KAPPLER, Claude - Monstruos, demonios y maravillas a fines de la Edad Media. Madrid: Akal, 2004, p. 132.

${ }^{8}$ Ibidem, p. 132.

${ }^{9}$ DASTON, Lorraine; PARK, Katharine - Wonders and the order of nature. New York: Zone Books, 1998, p. 52. 
inconscientes del ser humano [...] son seres deformes, hijos de lo desordenado, de lo extraño", ${ }^{10}$ definiéndose como "un prototipo de la fealdad". ${ }^{11}$

Cabe destacar que la palabra monstruo deriva del latín monstrum, esto es, monstruo, prodigio, maravilla y cosa increíble, lo que a su vez deviene de monstro, es decir, mostrar, indicar y señalar. ${ }^{12}$ San Agustín, en el siglo VI, anota un interesante pasaje en su obra La ciudad de Dios donde define la naturaleza monstruosa:

"Como no fue imposible para Dios crear las naturalezas que quiso, no lo es tampoco cambiarlas a su gusto. De aquí nacen todas esa serie de milagros que se llaman monstruos, ostentos, portentos y prodigios [...] Se dice que la palabra monstruo deriva de monstrando, y se llaman así porque muestran en cierta medida el futuro". ${ }^{13}$

Claramente podemos apreciar cómo lo monstruoso es un género de criaturas que muestra, presenta y pronostica algo con un significado. Son seres que difieren de las formas tradicionales de la creación o del canon de 'normalidad' del ser humano, centrando su esencia en la deformación o alteración del cuerpo y su naturaleza. ${ }^{14}$

David A. Williams señala que el discurso monstruoso se define en base a la deformidad, como también en relación a los signos, en el cual el monstruo adquiere una función literal y otra simbólica. La noción de 'signo literal' alude a la tradición geográfica y teratológica que indica las razas que habitan las regiones lejanas del mundo, las cuales se cree que existen

\footnotetext{
${ }^{10}$ WALDE MOHENO, Lillian von der - "Lo monstruoso medieval". La experiencia literaria, n. 2 (1993-1994), p. 48.

${ }^{11}$ Ibidem, p. 48.

${ }^{12}$ ECHAURI, Eustaquio - Diccionario Esencial VOX Latino-Español. Barcelona: Larousse, 2008, p. 278.

${ }^{13}$ SAN AGUSTÍN - La Ciudad de Dios. Madrid: Biblioteca de Autores Cristianos, 1958, XXI, 8, 5.

${ }^{14}$ Cabe destacar cómo San Agustín menciona una serie de monstruos que muestran alteraciones corporales y expresan un sentido de bestialidad. Entre ellos habla de cíclopes, pigmeos, esciápodos, cinocéfalos, seres que no tienen boca, entre otros. El obispo de Hipona considera que estas criaturas conforman parte de la Creación de Dios: "La razón que se da entre nosotros de los partos monstruosos, esa misma puede servir para pueblos enteros. Dios, que es el Creador de todas las cosas, conoce dónde, cuándo y qué es o ha sido oportuno crear, y además conoce la belleza del universo y la semejanza o diversidad de las partes que la componen" [Ibidem, XVI, 8, 2].
}

Medievalista online $N^{\circ} 20$ | Julho - Dezembro 2016 ( ) IEM - Instituto de Estudos Medievais 8 
físicamente. Por otra parte, la noción de ‘signo figurativo o metafórico’ se refiere al monstruo como una figura simbólica, la cual busca representar algo en particular o transmitir un mensaje con un sentido trascendente. ${ }^{15}$

Según Victoria Cirlot, lo monstruosis, horribilibus, es una especie, una raza y un género de seres deformes, los cuales se ubican en los lugares más recónditos de la tierra. ${ }^{16}$ Los monstruos están situados en el cosmos como parte de la Creación. Estos existen en diferentes niveles, pasando por los más comunes que son el humano, el animal y el mineral, predominando su carácter orgánico, anómalo e irracional. ${ }^{17}$ Junto con esto, Chet van Duzer señala que el concepto de lo monstruoso es muy difícil de definir, pues para algunos este prodigio se concibe como una forma del plan divino, un adorno del universo, que también puede enseñar acerca de los peligros del pecado. Pero además el monstruo puede reflejar lo sorprendente y lo exótico mediante las deformaciones físicas y morales de su ser. ${ }^{18}$ Ya Marco Polo en su obra el Libro de las cosas Maravillosas, compuesta entre 1298 y 1299 , se refiere a los monstruos de la isla de Gama o Angamanain:

"Gama es una isla que no tiene rey y sus habitantes son idólatras. De tal manera son como bestias salvajes, que todos sus habitantes tienen cabeza de

\footnotetext{
${ }^{15}$ WILLIAMS, David A. - Deformed discourse. The function of the Monster in Mediaeval Thought and Literature. Exeter: University of Exeter Press, 1996, pp. 11-12.

${ }^{16}$ CIRLOT, Victoria - "La estética de lo monstruoso en la Edad Media". Revista de Literatura Medieval, n. 2 (1990), pp. 177-178.

${ }^{17}$ SANTIESTEBAN, Héctor - "El monstruo y su ser". Relaciones, n. 81, vol. XXI (2000), pp. 96-97.

${ }^{18}$ VAN DUZER, Chet - "Hic sunt dracones: the geography and cartography of monsters". in MITTMAN, Asa; DENDLE, Peter (eds.) - The Ashgate Research Companion to Monsters and the Monstrous. FarnhamBurlington: Ashgate Variorum, 2012, p. 388. Hay que tener presente que existen diferentes variedades de monstruos que conforman parte del universo simbólico y cultural de la Edad Media. Claude Kappler realiza una interesante tipología, en la cual señala que hay monstruos que defieren de los seres normales según una asimetría absoluta (hacen lo contrario de lo que nosotros hacemos); los que carecen de algo esencial (monstruos sin cabeza, otros con cabeza pero sin ojos, nariz y labios, otros sin lengua, sin articulaciones en las rodillas, los que deben su monstruosidad al clima, etc.); monstruos por cambios en la relación entre sus órganos (las orejas, panotios; un pie, esciápodas; monoculi, seres con un solo ojo); monstruos caracterizados por la grandeza o pequeñez del cuerpo (gigantes, animales enormes, pigmeos); monstruos con mezclas de animales, minerales y vegetales (cordero vegetal, árbol de las ocas, vegetal humano); mezcla de sexos (andróginos); hibridación o mezcla de elementos humanos y animales (mantícora, cinocéfalo, sátiros), entre otros [KAPPLER, Claude, Monstruos, demonios y maravillas a fines de la Edad Media, p. 137 ss.]. Para una mayor revisión sobre la tipología de monstruos, véase: MITTMAN, Asa; DENDLE, Peter (eds.) - The Ashgate Research Companion to Monsters and the Monstrous. Farnham-Burlington: Ashgate Variorum, 2012; y FARGA MULLOR, María del Rosario - Monstruos y prodigios. El universo simbólico desde el Medievo a la Edad Moderna. Puebla: Universidad Iberoamericana Puebla, 2011.
} 
perro y sus dientes y su nariz semejan los de un gran mastín. Tiene especias en abundancia. Son tan mala gente, que se comen a cuantos hombres pueden coger, con tal que no sean de los suyos."19

Los monstruos son asociados a bestias salvajes, los cuales se vislumbran como seres perversos que se devoran a otros y provocan destrucción. Lo monstruoso adquiere un carácter negativo. En el caso relatado por Marco Polo, podemos observar cómo los cinocéfalos, hombres que tienen cabeza de perro, oscilan entre la figura humana y animal. ${ }^{20} \mathrm{Su}$ naturaleza se basa en la hibridación, es decir, en un cruce de sujetos en los que se mezclan elementos de especies diferentes. ${ }^{21}$ En cierta medida, el monstruo refleja un desorden de la naturaleza, la impureza y el peligro, pues su esencia se basa en actos salvajes e irracionales.

Del mismo modo, Guillermo de Rubruck en su informe Viaje por el Imperio Mongol, realizado en 1253, menciona un monstruo del cual le hablan en Cathay:

"Un día un sacerdote de Cathay estaba sentado conmigo, quien iba vestido con el mejor tono rojo, y le pregunté de dónde venía ese color; y él me dijo que en los países del este de Cathay existen unas rocas altas, entre las que habitan unas criaturas que tienen en todo forma de hombres, con la excepción de que sus rodillas no se doblan, más para moverse realizan algún movimiento saltando; y no tienen más de un codo de largo, y todo su pequeño cuerpo está cubierto de pelo, y viven en cavernas inaccesibles". ${ }^{22}$

\footnotetext{
${ }^{19}$ POLO, Marco - Viajes Il Milione. Barcelona: Iberia, 1957, CXLIX, p. 182.

${ }^{20}$ Cabe señalar que la naturaleza de los cinocéfalos oscila entre lo humano y lo animal. Tal como indica Paolo Vignolo, "la raza de los hombres perros es definida, antes que todo, por su relación ambigua entre el acto de hablar y el de ladrar [...] Son seres que comen viandas crudas, ya que no conocen el uso del fuego, pero las calientan al sol; no usan camas, sin embargo se acuestan sobre hojas secas, para evitar dormir al contacto directo con el suelo; tienen relaciones sexuales en cuatro patas, como perros, pero consideran indecente cualquier otra posición" [VIGNOLO, Paolo - "Una nación de monstruos. Occidente, los cinocéfalos y las paradojas del lenguaje". Revista de Estudios Sociales, n. 27 (2007), p. 141].

${ }^{21}$ KAPPLER, Claude - Monstruos, demonios y maravillas a fines de la Edad Media..., p. 167.

${ }^{22}$ RUBRUCK, Friar William of - The Journey to the Eastern Parts of the World, 328. London: The Hakluyt Society, 1900.
} 
Incluso, el fray Giovanni Pian de Carpine señala en su obra Historia de los Mongoles, redactada entre 1245 y 1247, cómo le cuentan sobre la presencia de monstruos en Oriente:

"Pero a medida que los tártaros cruzaron un desierto descubrieron ciertos monstruos (como nos informaron a nosotros), que tenían un solo brazo en medio del estómago, y sólo un pie [...], y corrían tan rápido que con los caballos no podían capturarlos. Corrían saltando en un pie, y cuando se cansaban de ir de esa manera, luego marchaban sobre una mano y un pie girando como una rueda." 23

Claramente lo monstruoso se manifiesta en ambos pasajes, donde las criaturas reflejan formas grotescas y descomunales que exceden la naturaleza humana, distinguiéndose por su rareza, anomalía y desproporción. El monstruo es así, por naturaleza, insólito, deforme e imperfecto. Junto con esto, el autor anónimo del Libro del Conosçimiento, escrito hacia 1385, se refiere a los monstruos que se encuentran en la tierra de Gothia: "Y es tierra desabitada pero que dizen que son fallados enesta tierra ommes que han las cabeças pegadas sobre los ombros que non han cuellos ningunos". ${ }^{24}$ Asimismo, en la obra Historia de las Cruzadas de Jacques de Vitry, redactada hacia 1219 y 1220, encontramos la mención de la mantícora:

"Otro animal monstruoso que se llama mantícora, tiene cara de hombre, cuerpo de león, cola de escorpión, triple hilera de dientes en la mandíbula, la tez roja, los ojos verdosos y silba como una serpiente. Su silbido es tan sonoro que imita las modulaciones de la flauta. Busca carne humana con gran avidez. Es tan rápido en la carrera como un pájaro en vuelo". 25

Los monstruos que se encuentran en los márgenes poseen formas extrañas y misteriosas. No se puede concebir como algo simétrico y ordenado, sino que por el contrario, su cuerpo conlleva lo desmesurado y lo caótico. El monstruo es la antítesis de lo ideal. Tal como

\footnotetext{
${ }^{23}$ CARPINE, Giovanni de Pian de - The Story of the Mongols. Boston: Branding Publishing Company, 1996, p. 69. La traducción es mía.

${ }^{24}$ LIBRO DEL CONOSÇIMIENTO. Trad. Marcos Jiménez de la Espada. Madrid: Imprenta de T. Fortanet, 1877, XCIV, p. 115.

${ }^{25}$ VITRY, Jacques - Historia de las Cruzadas. Buenos Aires: Eudeba, 1991, pp. 106-107.
} 
manifiesta Mary B. Campbell, el cuerpo idealizado del hombre es una imagen de Dios, por lo cual, lo grotesco son las formas horribles opuestas al canon clásico. ${ }^{26}$ Esto se vislumbra en la imagen de los hombres que tienen la cabeza pegada sobre los hombros, sin un cuello que conecte ambos miembros. Asimismo, esto se percibe en la mantícora, la cual posee un rostro de persona y un cuerpo híbrido de distintos animales. El monstruo se concibe como fruto de la deformidad. ${ }^{27}$ Asimismo, John Mandeville en su Libro de las Maravillas del Mundo, escrito hacia 1365 y 1371, anota una variedad de monstruos ubicados en las islas del confín del mundo:

"Los habitantes de otra isla tienen los ojos y la boca en la espalda, a la zaga de los hombros. En otras, hay gentes con la cara totalmente aplanada, sin nariz y sin ojos, con dos agujeros redondos horadados en el lugar de los ojos y una raja en vez de boca y labios [...] Otros hombres monstruosos tienen la cara muy deformadas, con el labio inferior tan enorme que, cuando quieren dormirse al sol, llegan a taparse toda la cara con sus mismos labios [...] Asimismo, se halla en otra isla una raza de hombres cuyas enormes orejas les cuelgan hasta las rodillas. Los hay también con piel de cabra, pero fuertes y valientes, porque son capaces de ganar a las fieras, cuando corren detrás para apresarlas y comérselas. Otra clase de gente montaraz son los que andan a gatas, como los animales. Son tan vellosos que parecen osos y trepan por los árboles tan prestos como monos". ${ }^{28}$

\footnotetext{
${ }^{26}$ CAMPBELL, Mary B. - The witness and the other world. Exotic European travel writing, 400-1600. New York: Cornell University Press, 1991, p. 77.

${ }^{27}$ Cabe mencionar que "cada familia de monstruos representa una forma de alteración, sea por el aumento del tamaño de su cuerpo o su reducción, por el añadido de miembros o por su falta, por la aparición de miembros del cuerpo en lugares insospechados o por la mezcla de todas estas alteraciones [...] Los cíclopes no tienen más que un ojo, los esciápodos, un solo pie. Y, a la inversa, algunos monstruos tienen varias piernas y hay seres bicéfalos y tricéfalos". Asimismo, se encuentra "la amplia familia de híbridos (cinocéfalos, sirenas, centauros, etc.), que proceden de mezclas contrarias a las reglas de la naturaleza, pues se confunden géneros y especies, y se combinan rasgos humanos y animales" [RUBIO TOVAR, Joaquín - "Monstruos y seres fantásticos en la literatura y pensamiento medieval". in VV.AA. - Poder y seducción de la imagen románica. Aguilar de Campóo: Universidad de Alcalá de Henares, 2006, pp. 131-132].

${ }^{28}$ MANDEVILLE, John - El Libro de las Mara villas del Mundo. Ed. M.-J. Lemarchand. Madrid: Siruela, 2002, Libro II, XXIV, pp. 208-209.
} 
Las razas monstruosas se sitúan en los espacios lejanos e inaccesibles, en las tierras incógnitas e inexploradas. El monstruo se percibe como algo alejado; está en la selva, en el desierto, en Asia, África, la India o los confines del mundo. El monstruo es lo ‘malo’ que se excluye de la vida civilizada. ${ }^{29}$ Tal como expresa Victoria Cirlot, "la ubicación de los monstruos en los lugares recónditos del universo, lo convierten en un ser jamás visto. Parece que en su esencia el monstruo gusta de ocultarse". ${ }^{30}$ En otras palabras, el monstruo escapa de lo cotidiano, se torna un ser extraño, diverso y lejano. En el pasaje de John Mandeville, podemos vislumbrar cómo las criaturas se ubican en diferentes islas de Oriente, reflejando una variedad de prodigios deformes e híbridos bestiales. Ahora bien, tal como considera Rudolf Wittkower, estas razas fabulosas son producto de la voluntad de Dios. ${ }^{31}$ No se puede concebir a estas criaturas como parte de un error de la naturaleza, ni menos como algo que sea contrario al plan omnipotente. Dios ha creado a los monstruos con un propósito superior, donde las razas humanas y monstruosas conforman parte de un todo, expresando el asombroso poder divino. ${ }^{32}$

\section{III}

\section{Los monstruos en las Andanças e viajes de Pero Tafur}

El concepto de lo monstruoso refleja un desorden dentro de la naturaleza, dando cuenta de una anormalidad corporal o física, o en las actitudes barbáricas y bestiales de las criaturas. Lo monstruoso representa una anomalía que escapa de las formas tradicionales de la naturaleza y que conlleva a lo inferior y lo grotesco. En el caso de Pero Tafur, si bien se mira en ciertos momentos con escepticismo el carácter monstruoso, éste se encuentra presente en su obra mediante criaturas bestiales y gentes deformes y barbáricas. Nicolo de Conti le advierte en un momento a Tafur los peligros y monstruosidades de Oriente:

\footnotetext{
${ }^{29}$ WALDE MOHENO, Lillian von der - "Lo monstruoso medieval", pp. 48-49; y LECLERCQ-MARX, Jacqueline - "Monstruos en la escritura, monstruos en las imágenes. La doble tradición medieval". Quintana, n. 4 (2005), p. 24.

${ }^{30}$ CIRLOT, Victoria - "La estética de lo monstruoso en la Edad Media...", p. 178.

${ }^{31}$ WITTKOWER, Rudolf - "Marvels of the East. A study in the history of monsters". Journal of the Warburg and Courtauld Institutes, vol. 5 (1942), p. 176.

${ }^{32}$ BOVEY, Alixe - Monstruos y grutescos en los manuscritos medievales. Madrid: AyN Ediciones, 2006, p. 10 .
} 
"En lo que a ti te toca, yo te ruego por Dios y por el amor que te he, pues eres cristiano e de la tierra donde yo soy, que no te entrometas en tan gran locura, porque el camino es muy largo e trabajoso e peligroso, de generaciones estrañas sin rey e sin ley e sin señor [...] Después, mudar el aire e comer e beber estraño de tu tierra, por ver gentes bestiales que no se rigen por seso e que, bien que algunas monstruosas aya, no son tales para aver placer con ellas". ${ }^{33}$

El carácter monstruoso se manifiesta en las gentes bestiales de las tierras lejanas. En cierta medida, es una monstruosidad vinculada al salvajismo y barbarie que se retrata de los pueblos de Oriente. Esto es así, ya que no se rigen por el juicio y la razón, sino que se dejan llevar por los instintos de las bestias y animales. Es una naturaleza monstruosa, basada en las actitudes y costumbres que se alejan de un orden civilizado. ${ }^{34} \mathrm{El}$ monstruo es lo opuesto, una manifestación del desorden y una imagen del mal. ${ }^{35}$ Raúl Dora sostiene que "el monstruo suele definirse en relación con una norma que resulta violada; es una deformación o un desvío del orden natural o del orden divino; es una desmesura o una carencia que violenta la armonía de los seres". ${ }^{36}$ La monstruosidad se retrata como un campo que genera terror por su naturaleza desviada e imperfecta. ${ }^{37}$ Asimismo, el caballero sevillano alude el caso de la gente bestial de Cafa:

${ }^{33}$ TAFUR, Pero - Andanças e viajes..., p. 96.

${ }^{34}$ Tal como señala Claude Kappler, son gentes que viven como animales, caracterizadas por la ausencia de una organización social y religiosa. En cierta medida, es el desprecio de los más civilizados el que les atribuye esa característica bestial, una bestialidad que reside en el hecho de que viven sin ley [KAPPLER, Claude Monstruos, demonios y maravillas a fines de la Edad Media..., p.179].

${ }^{35}$ Ibidem, p. 248.

${ }^{36}$ Cabe destacar que la monstruosidad puede tratarse de un desorden físico, de un desorden moral (la excesiva maldad, lujuria y carencia de todo sentimiento humano), e incluso de un desorden estético (la fealdad extrema y la turbadora belleza de efectos demoníacos) [DORA, Raúl - "¿Para qué los monstruos?". Elementos, n. 22, vol. 3 (1994), p. 15].

${ }^{37}$ Según Juan Casas Rigall, el viajero español al alejarse de los pueblos más civilizados, aun sin salir de Europa, comienza a tener atisbos de monstruosidad. Así, en Esclavonia se puede advertir que los habitantes, de altura poco común, son las gentes más crecidas y salvajes que ha visto [CASAS RIGALL, Juan - "Razas humanas portentosas en las partidas remotas del mundo (de Benjamín de Tudela a Cristóbal Colón)". In BELTRÁN, Rafael - Maravillas, peregrinaciones y utopías: literatura de viajes en el mundo románico. Valencia: Universitat de València, 2002, pp. 276-277]. 
"E mucho quisiera yo tenerme en estas tierras, mas por ser gentes bestiales e por los mantenimientos no ser conformes a mi naturaleza e porque es como cerradura cuasi a la India Mayor, que es imposible de ir, e en las otras tierras no ay que ver sino gentes destruidas y gastadas [...] Tanta es la bestialidad e deformidad de aquesta gente que de buena voluntad yo abrí mano del deseo que tenía de ver adelante e tomé la vuelta a la Grecia e partí de Cafa, recogidas todas mis cosas". ${ }^{38}$

El viajero anota el carácter monstruoso basado en una oposición a su naturaleza, donde las gentes, sus formas y costumbres son bestiales. El monstruo es un ser pecaminoso, por lo cual, va en contra de la naturaleza del viandante. Tal como señala Héctor Santiesteban, pecar es no obedecer a la natura, pues ésta siempre es recta y nunca peca. ${ }^{39}$ La monstruosidad de esta gente es vista como una manera de apartarse de lo normal y lo natural. Junto con esto, Claude Kappler indica que el monstruo, hijo del desorden, refleja una imagen de deformidad y se considera como enemigo de lo bello. ${ }^{40}$ En este sentido, es posible apreciar cómo las gentes de Cafa son seres desproporcionados y salvajes, considerándolos monstruos por su fealdad y rareza. Son criaturas que se asocian a lo malvado y desvirtuado, alejados de toda rectitud, infundiendo rechazo y temor, lo que hace que el mismo viajero se marche de aquellas tierras

\footnotetext{
${ }^{38}$ TAFUR, Pero - Andanças e viajes..., p. 146.

${ }^{39}$ SANTIESTEBAN, Héctor - "El monstruo y su ser...", p. 109. Cabe señalar que en la teología medieval los pecados reflejan los vicios que corrompen el alma [MORIN, Alejandro - "Pecado e individuo en el marco de una antropología cristiana medieval". Bulletin du centre d'études médiévales d'Auxerre, BUCEMA, n. 2 (2008), p. 5]. Ahora bien, resulta importante considerar este concepto desde otra perspectiva, tal como es el caso del pecado original, en el cual el pecado de Adán ha hecho a todos pecadores. Para San Agustín de Hipona, en él todos somos uno, pues todos hemos pecado en él. No es un pecado cometido en voluntad propia, sino que todas las personas contraen la culpa de Adán. Pedro Lombardo señala que el pecado original es una culpa que se transmite por los padres a todos los que son engendrados por concupiscencia, esto es, el deseo desmedido como obra del mal. San Anselmo sostiene que el pecado es una ofensa contra el honor de Dios. Incluso, Santo Tomás de Aquino vislumbra el pecado original como la privación del estado original, donde el hombre tiene una radical incapacidad para la recepción de la gracia. En otras palabras, el pecado original refleja una disposición de la naturaleza, que solo es de cada persona en la medida en que recibe la naturaleza del primer padre. En cuanto a los efectos del pecado original, Santo Tomás indica que los principios mismos de la naturaleza no se pierden a causa del pecado de Adán, pero la inclinación a la virtud disminuye y se priva al hombre del estado original [LADARIA, Luis - Teología del pecado original y de la gracia. Antropología teológica especial. Madrid: Biblioteca de Autores Cristianos, 1993, pp. 89-94]. Pero bien, en el caso de los monstruos, éstos constituyen un ser pecaminoso en la medida que reflejan un híbrido y contraejemplo natural, donde el pecado no es otra cosa que apartarse de la naturaleza.
}

${ }^{40}$ KAPPLER, Claude - Monstruos, demonios y maravillas a fines de la Edad Media..., pp. 248-249. 
por tanta monstruosidad. ${ }^{41}$ Por otro lado, el caballero sevillano menciona el caso del cocodrilo en el Nilo:

"Ay en esta ribera unas bestias que se crían dentro del agua, que llaman cocatriz, las cuales, cuando están en al agua, no ay ome ni bestia que puedan alcançar que no la matan [...] Ésta es en todo fechura de lagarto, tienen los dientes macho e fembra arriba e abaxo, e por esto dizen que, cuando travan de alguna cosa, no pueden soltar tan aína". ${ }^{42}$

Incluso, el mismo viajero se refiere al cuero de esta bestia como cosa monstruosa: "E aun allí están ciertos cueros de aquellas bestias que dizen cocatrizes, que el soldán de Babilonia, por cosa mostruosa, embió presentados a la Señoría, éste es un notable palacio". ${ }^{43}$

Mediante estos pasajes podemos vislumbrar cómo el cocodrilo y su naturaleza se conciben como algo monstruoso. El viajero asocia este animal a una bestia salvaje que se mueve por las aguas, caracterizándose por su forma de lagarto, sus grandes dientes y su sorprendente fuerza. Cabe señalar que en los textos medievales se encuentra la voz de cocatriz referida a hydrus, es decir, una 'manera de serpiente', 'hidra' o 'serpiente de agua'. ${ }^{44}$ Es una bestia que suscita temor; la comunicación con el animal no existe, es lo impenetrable y lo extraño por excelencia, el hombre proyecta en aquél sus angustias y sus terrores. ${ }^{45}$ Es un monstruo que refleja una fuerza descomunal y una naturaleza feroz. En este caso, si bien el cocodrilo se concibe como parte de la creación de Dios, también resulta ser una bestia única y diferente, la cual se encuentra en tierras exóticas y lejanas que le otorgan su condición maravillosa. ${ }^{46}$

\footnotetext{
${ }^{41}$ Según Victoria Béguelin-Argimón, el caballero Pero Tafur estando en Cafa, califica a su población de bestial y deforme, sustrayéndola así de esta humanidad que es la conditio sine qua non para la aceptación del Otro. Tal es el rechazo que experimenta que decide abandonar la ciudad y renuncia a continuar su ruta hacia Oriente [BÉGUELIN-ARGIMÓN, Victoria - "Lo maravilloso en tres relatos de viajeros castellanos del siglo XV". in PEÑATE, Julio - Relato de viaje y literatura hispánica. Madrid: Visor Libros, 2004, pp. 90 ss.].

42 TAFUR, Pero - Andanças e viajes..., p. 79.

${ }^{43}$ Ibidem, p. 179.

${ }^{44}$ ARES, Alida - "Sobre el término medieval cocatriz, variantes y acepciones". Revista de Lexicografía, vol. 3 (1996-1997), pp. 7-30.

45 MALAXECHEVERRÍA, Ignacio - "Bestiario y bestiarios. El animal y el hombre". in Bestiario medieval. Madrid: Siruela, 2002, p. 15.

${ }^{46}$ Cabe mencionar como Tafur también se refiere al hipopótamo como una bestia grotesca: "Dizen muchos yo no lo vi- que en esta misma ribera se crían otras bestias que son cavallos ni más ni menos, salvo que lo de la boca tienen tan ancho como de la frente, e salen pegado con el agua a pacer e allí les arman unos hoyos cubiertos,
}

Medievalista online № 20 | Julho - Dezembro 2016 (c) IEM - Instituto de Estudos Medievais 16 www2.fcsh.unl.pt/iem/medievalista 
Finalmente, el caballero sevillano se refiere a un monstruo que aparece en la ciudad de Spalato:

"E fue así que un día, estando las mugeres en el agua como solían, un mostruo, medio pescado de la cinta ayuso e de allí arriba forma humana, con alas como morciélago - e esta figura en Castilla fue traída e por todo el mundo-, arremetió a una muger e travó de ella e metióla al fondo del agua, e dio vozes e fue acorrida de las otras luego e de muchos ombres que cerca de allí estaban, e fueron e falláronla cómo el mostruo la tirava dentro e ni por su venida de ellos la queríe soltar. E allí lo ferieron e sacaron en tierra vivo, e estuvo tres oras e más que no murió. E de allí se cree que las mugeres que de ante fallecían, aquellas oviese fecho menos, e abriéronlo e saláronlo e embiaron a la Señoría de Veneja, para que lo embiase al Papa Eugenio. Esto yo no lo vi, pero dicho me fue e que avía poco que avia acaecido". ${ }^{47}$

La anotación del carácter monstruoso se manifiesta de manera clara. Tafur narra el caso de un híbrido, el cual posee en su parte superior forma humana con alas de murciélago y en su parte inferior cuerpo de pez. Si bien le cuentan a Tafur esta leyenda, él mismo indica que es algo que había ocurrido hace poco, donde el monstruo fue capturado y enviado a Venecia para que pudiera ser examinado por el Papa. ${ }^{48}$ Es un monstruo que sorprende por su carácter humano y animal, donde la hibridación altera la anatomía, generando miembros dispares y raros en el cuerpo de la criatura. El monstruo refleja lo extraño y lo distinto, una fuerza aterradora y espeluznante. ${ }^{49}$

como llaman en Castilla loberas, e allí los matan" [TAFUR, Pero - Andanças e viajes, p. 79]. Incluso, se refiere a los montes de tigres en Cracovia: "E allí quisiera yo ir a ver a Cracovia, que es la mayor cibdad de su reino, e no pude quisiera verle correr monte de tigres, que es la más señalada cosa que se faze en aquellas partes, que son bestias muy bravas e muy peleadoras e muy ligeras" [Ibidem, p. 229]. Claramente podemos apreciar cómo la bestia es lo grotesco, lo salvaje y lo distinto. El cuadro de lo monstruoso se caracteriza por el exceso, lo que es completamente diferente de lo cotidiano, aquello que resulta llamativo por su rareza.

${ }^{47}$ Ibidem, p. 165.

${ }^{48}$ GARROSA, Antonio - "La tradición de animales fantásticos y monstruos en la literatura medieval española". Castilla: estudios de literatura, n. 9-10 (1985), p. 83.

${ }^{49} \mathrm{El}$ mismo viajero se refiere a las sirenas en la ciudad de Messina: "Este Faro es el mar do fingen los poetas que ay las sirenas [...] E dizen que esta natura de pescados en parte parece fembra de la cinta arriba e de allí abaxo pescado, que está posada en este fondón, donde es el primer movimiento de los vientos e, como ellas sienten el viento que se mueve e cuán vigoroso será, sintiendo que de la gran fortuna se puede proceder, ellas 
Según Ángel Luis Molina y Anca Crivat-Vasile, el viajero se muestra escéptico e incrédulo ante este tipo de eventos y utiliza expresiones como "yo no lo vi" o "dizen", desprendiéndose de la responsabilidad de narrar estos acontecimientos sobrenaturales. ${ }^{50}$ En cierta medida, es posible apreciar cómo el fenómeno monstruoso no se narra como algo visto de manera directa, sino que utiliza expresiones donde son otras gentes quienes le cuentan el suceso prodigioso. ${ }^{51}$ Ahora bien, dicha modalidad narrativa es característica del cuadro de las maravillas de los viajeros medievales, en cuanto los diferentes viajeros no vislumbran todos los eventos sobrenaturales, sino que muchos les son contados por extranjeros y gentes locales con quienes dialogan. Cabe mencionar que el escepticismo e incredulidad ya conforma parte en algunos pasajes de los viajeros medievales con la anotación de diversos monstruos o criaturas portentosas. En el Libro del Conosçimiento el autor anónimo indica: "E sabed que desde Noruega adelante contra la Trasmontana es tierra desabitada en que faze el año todo vn dia seys meses dura el dia y otros seys meses la noche y que ay vnas gentes que an las cabeças fixas en los pechos que non an cuello ninguno pero yo non los vy". ${ }^{52}$ Marco Polo también aplica la misma fórmula:
"La salamandra no es un animal, como se dice, que viva en el fuego; yo os diré como se extrae la salamandra. Un compañero mío, llamado Zuficar, es un turco que estuvo como gobernador, mandado por el Gran Kan: pasó tres años en aquella comarca, y hacía extraer esta salamandra; él me lo dijo a mí, y era persona que lo hizo muchas veces, aunque yo no lo vi". 53

\footnotetext{
se muestran en la cara del agua faziendo un canto. E dizen que quien las oye no puede bevir, esto es, que es triste canto condoliéndose de aquella fortuna que se apareja a aquellos a quien ellas parecen, e el no bevir es porque ellas nunca cantan sino cuando la fortuna es tan grande que aquellos que están en la mar seríe maravilla escapar" [TAFUR, Pero - Andanças e viajes..., p. 248]. Si bien la mención de las sirenas responde a lo que cuentan los poetas, el carácter monstruoso queda manifiesto al incluirlo en su libro de viajes, como una manera de indicar qué tipo de criaturas prodigiosas perviven en la mentalidad de la sociedad occidental.

${ }^{50}$ MOLINA MOLINA, Ángel Luis - "Pero Tafur, un hidalgo castellano en Tierra Santa y Egipto...", p .643 y CRIVAT-VASILE, Anca - "Mirabilis Oriens: fuentes y transmisión...", p. 478.

${ }^{51}$ Según Juan Casas Rigall la usual fórmula "Yo non lo vi" excluye expresamente la anécdota del dominio de la observación personal. Sin embargo, el aserto de que el prodigio fue llevado a Castilla, así como la procedencia de la información - testigos presenciales -, hacen pensar que Tafur concede crédito al suceso [CASAS RIGALL, Juan - "Razas humanas portentosas en las partidas remotas del mundo (de Benjamín de Tudela a Cristóbal Colón)...", p. 276].

${ }^{52}$ LIBRO DEL CONOSÇIMIENTO..., VII, pp. 16-17.

${ }^{53}$ POLO, Marco - Viajes Il Milione..., XLVIII, pp. 68-69.
} 
Incluso, Jacques de Vitry luego de referirse a los arimaspos, cíclopes, hombres salvajes, grullas, entre otros, señala:

\begin{abstract}
"Si alguien no quiere concederles fe, no pretendemos forzarlos a creer; 'que cada uno actúe según la plena persuasión de su espíritu' (Ro., 14, 5). Nosotros pensamos que no hay peligro en creer en las cosas que no están reñidas por la fe y la buena moral. Sabemos que todas las obras de Dios son admirables; sin embargo, ocurre que quienes están acostumbrados a ver ciertas cosas ya no sienten admiración alguna". 54
\end{abstract}

Mediante estos fragmentos podemos apreciar cómo en la tradición de los viajeros medievales, éstos mismos pueden dudar o no mostrar certeza de las criaturas extraordinarias de las cuales escuchan relatos. Sin embargo, no las niegan, puesto que los seres monstruosos conforman parte de la creación y se encuentran ubicados en los extremos del mundo, como parte de tierras lejanas, exóticas y desconocidas. En este sentido, no existe una ruptura con el cuadro narrativo de lo monstruoso del mundo medieval, sino que este recurso se aplica dentro de las Andanças e viajes, donde los monstruos y las bestias no dejan de estar presentes para dar cuenta de lo raro y lo grotesco de algunas criaturas existentes en la creación.

\title{
IV
}

\section{A modo de conclusión}

Como balance final podemos sostener que la categoría de lo monstruoso se encuentra presente en la obra de Tafur, dando cuenta de las anomalías, excesos y diferencias que existen en algunos pueblos grotescos, criaturas híbridas y animales bestiales. El monstruo expresa la diferencia, pero al mismo tiempo constituye aquello que genera sorpresa, estupefacción, terror y maravilla. Tal como expresa Jean Verdon, el monstruo posee una naturaleza dual, en la medida que es maravilloso porque emana del Creador, pero posee poderes perniciosos. ${ }^{55}$

\footnotetext{
${ }^{54}$ VITRY, Jacques - Historia de las Cruzadas..., p. 116.

55 VERDON, Jean - Travel in the Middle Ages. Notre Dame: University of Notre Dame, 2003, p. 291.
} 
En el caso de Tafur, la figura del monstruo se manifiesta a través de seres prodigiosos, bestias salvajes y criaturas barbáricas. Si bien en algunos casos el autor presenta una postura crítica, racional o escéptica frente a ciertos monstruos o maravillas, la mención de estos componentes asombrosos no está ausente en su relato. El viajero español menciona algunos seres monstruosos, ya sea porque desconoce a las criaturas que observa y busca anotar la rareza de dichas bestias, como también por la tradición socio-cultural y simbólica plasmada en el imaginario medieval sobre Asia, es decir, una tierra exótica y lejana, receptáculo de seres extraños y maravillosos.

Junto con esto, el problema que se menciona acerca de la incredulidad y escepticismo en el viajero sevillano, ya sea aplicando fórmulas como "dizen" o "yo no lo vi", no es algo que nos permita desechar el uso de las maravillas en su obra. Por el contrario, es un modo narrativo en el cual se busca incluir precisamente las maravillas de las cuales se hablan y conforman parte de la mentalidad del mundo europeo. Sin ir más lejos, dicho recurso narrativo es utilizado por la misma tradición de los viandantes medievales, quienes si bien reflejan elementos sobrenaturales basados en la tipología de lo maravilloso, también en algunos casos presentan dudas o se muestran escépticos frente a eventos que no han podido presenciar. En otras palabras, el caballero español no se escapa de las fórmulas descriptivas y narrativas que aplican los viajeros que le anteceden, incluyendo las maravillas vistas y no vistas, es decir, aquellas que vislumbra presencialmente, como también las que le cuentan en sus desplazamientos. 56

En definitiva, Tafur conserva de manera matizada la tradición de los viajeros medievales, rescatando la figura del monstruo, tanto en su carácter nocivo, perverso y opuesto a los ideales y valores de la cristiandad, como también en un sentido deslumbrante y asombroso por las

\footnotetext{
${ }^{56}$ Cabe destacar que el viaje no está exento de imaginación: el asombro y la maravilla deslumbran por la naturaleza fabulosa y sorprendente. Tal como señala María Jesús Lacarra, el alejamiento espacial predispone al viajero para la sorpresa y la imaginación, donde el mundo de las maravillas constituye otra realidad más [Cfr. LACARRA, María Jesús - "La imaginación en los primeros libros de viajes". in TORO PASCUA, María Isabel (ed.) - Actas del III Congreso de la Asociación Hispánica de Literatura Medieval, Biblioteca Española del Siglo XV. Salamanca, 1994, p. 501]. Los viajeros, los lectores y los oyentes esperan los relatos con narraciones extraordinarias y pasmosas, donde no solo se observa otra realidad, sino que también pueden definir elementos propios de su cultura frente a una otredad completamente distinta.
} 
maravillas que posee Oriente. Estas razas fabulosas son producto de la creación divina. No pueden ser concebidas como un error de la naturaleza, sino que reflejan parte del plan omnipotente, donde Dios ha creado a los monstruos con un propósito superior: un fin didáctico, moral, de enseñar al hombre la rectitud, y dar cuenta de cómo la monstruosidad corrompe a los seres física y espiritualmente. Ahora bien, es importante destacar cómo los monstruos también expresan el asombroso poder divino, dando cuenta de creaciones singulares y maravillosas, las cuales sorprenden por su carácter único y distinto. En suma, la monstruosidad no solo debe ser vista en términos negativos, barbáricos y bestiales, sino que también significa un encuentro con lo extraño, fascinante y asombroso, y que permite conocer las verdades y maravillas del mundo.

\section{Referências bibliográficas:}

\section{Fuentes}

CARPINE, Giovanni de Pian de - The Story of the Mongols. Boston: Branding Publishing Company, 1996.

LIBRO DEL CONOSÇIMIENTO. Trad. Marcos Jiménez de la Espada. Madrid: Imprenta de T. Fortanet, 1877.

MANDEVILLE, John - El Libro de las Maravillas del Mundo. Ed. M.-J. Lemarchand. Madrid: Siruela, 2002.

POLO, Marco - Viajes Il Milione. Barcelona: Iberia, 1957.

RUBRUCK, Friar William of - The Journey to the Eastern Parts of the World. London: The Hakluyt Society, 1900.

SAN AGUSTÍN - La Ciudad de Dios. Madrid: Biblioteca de Autores Cristianos, 1958.

TAFUR, PERO - Andanças e viajes. Ed. Miguel Ángel Pérez Priego. Sevilla: Fundación José Manuel Lara, Clásicos Andaluces, 2009.

VITRY, Jacques - Historia de las Cruzadas. Buenos Aires: Eudeba, 1991.

\section{Estudios}

ARES, Alida - "Sobre el término medieval cocatriz, variantes y acepciones". Revista de Lexicografía, vol. 3 (1996-1997), pp. 7-30. 
BÉGUELIN-ARGIMÓN, Victoria - "Lo maravilloso en tres relatos de viajeros castellanos del siglo XV". in PEÑATE, Julio - Relato de viaje y literatura hispánica. Madrid: Visor Libros, 2004, pp. 87-99.

BELTRÁN, Rafael - "Libro de viajes medievales castellanos. Introducción al panorama crítico actual: ¿cuántos libros de viajes medievales castellanos?". Filología Románica, Anejo I (1991), pp. 121-164.

BOVEY, Alixe - Monstruos y grutescos en los manuscritos medievales. Madrid: AyN Ediciones, 2006.

DORA, Raúl - "¿Para qué los monstruos?". Elementos, n. 22, vol. 3 (1994), pp. 13-19.

CAMPBELL, Mary B. - The witness and the other world. Exotic European travel writing, 400-1600. Nueva York: Cornell University Press, 1991.

CARRIZO RUEDA, Sofía - "Símbolos, mitos y prodigios en el horizonte de los viajeros medievales". Quimera, Revista de Literatura, n. 246-247 (2004), pp. 12-20.

CASAS RIGALL, Juan - "Razas humanas portentosas en las partidas remotas del mundo (de Benjamín de Tudela a Cristóbal Colón)". in BELTRÁN, Rafael - Maravillas, peregrinaciones y utopías: literatura de viajes en el mundo románico. València: Universitat de València, 2002, pp. 253-285.

CASTRO HERNÁNDEZ, Pablo - "La tradición de las maravillas en las Andanças e viajes de Pero Tafur (1436-1439)". LEMIR, Revista de Literatura Española Medieval y del Renacimiento, n. 18 (2014), pp. 329-382.

CHEVALIER, Jean; GHEERBRANT, Alain - Diccionario de Símbolos. Barcelona: Herder, 1986.

CIRLOT, Victoria - "La estética de lo monstruoso en la Edad Media". Revista de Literatura Medieval, n. 2 (1990), pp. 175-182.

CRIVAT-VASILE, Anca - "Mirabilis Oriens: fuentes y transmisión". Revista de Filología Románica, n. 11-12 (1994-1995), pp. 471-479.

DALY, Karen M. - "Here there be no dragons: Maravilla in two fifteenth-century spanish libros de viajes". Notandum, vol. XV, n. 29 (2012), pp. 25-34.

DASTON, Lorraine; PARK, Katharine - Wonders and the order of nature. New York: Zone Books, 1998.

ECHAURI, Eustaquio - Diccionario Esencial VOX Latino-Español. Barcelona: Larousse, 2008.

Medievalísta online № 20 | Julho - Dezembro 2016 ( ) IEM - Instituto de Estudos Medievais 22 
FARGA MULLOR, María del Rosario - Monstruos y prodigios. El universo simbólico desde el Medievo a la Edad Moderna. Puebla: Universidad Iberoamericana Puebla, 2011.

GARROSA, Antonio - "La tradición de animales fantásticos y monstruos en la literatura medieval española". Castilla: estudios de literatura, n. 9-10 (1985), pp. 77-101.

KAPPLER, Claude - Monstruos, demonios y maravillas a fines de la Edad Media. Madrid: Akal, 2004.

LACARRA, María Jesús - "La imaginación en los primeros libros de viajes". in TORO PASCUA, María Isabel - Actas del III Congreso de la Asociación Hispánica de Literatura Medieval, Biblioteca Española del Siglo XV. Salamanca, 1994, pp. 501-509.

LADARIA, Luis - Teología del pecado original y de la gracia. Antropología teológica especial. Madrid: Biblioteca de Autores Cristianos, 1993.

LECLERCQ-MARX, Jacqueline - "Monstruos en la escritura, monstruos en las imágenes. La doble tradición medieval". Quintana, n. 4 (2005), pp. 13-53.

MALAXECHEVERRÍA, Ignacio - "Bestiario y bestiarios. El animal y el hombre". in Bestiario medieval. Madrid: Siruela, 2002, pp. 13-55.

MITTMAN, Asa; DENDLE, Peter (ed.) - The Ashgate Research Companion to Monsters and the Monstrous. Farnham-Burlington: Ashgate Variorum, 2012.

MOLINA MOLINA, Ángel Luis - "Pero Tafur, un hidalgo castellano en Tierra Santa y Egipto". Cuadernos de Turismo, n. 27 (2011), pp. 641-662.

MORIN, Alejandro - "Pecado e individuo en el marco de una antropología cristiana medieval". Bulletin du centre d'études médiévales d'Auxerre, BUCEMA, n. 2 (2008), pp. 216.

PÉREZ PRIEGO, Miguel Ángel - "Estudio literario de los libros de viajes medievales". Revista de Filología, n.1 (1984), pp. 217-239.

- "Maravillas en los libros de viajes medievales". Compás de Letras, n. 7 (1995) pp. 65-78.

RUBIO TOVAR, Joaquín - "Monstruos y seres fantásticos en la literatura y pensamiento medieval". in VV.AA. - Poder y seducción de la imagen románica. Aguilar de Campóo: Universidad de Alcalá de Henares, 2006, pp. 121-155.

SANTIESTEBAN, Héctor - "El monstruo y su ser". Relaciones, n. 81, vol. XXI (2000), pp. 93-126. 
TAYLOR, Barry - "Late medieval Spanish travellers in the East: Clavijo, Tafur, Encina and Tarifa". in ALLEN, Rosamund (ed.) - Eastward Bound: Travel and Travellers, 1050-1550. Manchester: Manchester University Press, 2004, pp. 221-234.

VAN DUZER, Chet - "Hic sunt dracones: the geography and cartography of monsters". in MITTMAN, Asa; DENDLE, Peter (ed.) - The Ashgate Research Companion to Monsters and the Monstrous. Farnham-Burlington: Ashgate Variorum, 2012, pp. 387-435.

VERDON, Jean - Travel in the Middle Ages. Notre Dame: University of Notre Dame, 2003.

VIGNOLO, Paolo - "Una nación de monstruos. Occidente, los cinocéfalos y las paradojas del lenguaje". Revista de Estudios Sociales, n. 27 (2007), pp. 140-149.

WALDE MOHENO, Lillian von der - "Lo monstruoso medieval". La experiencia literaria, n. 2 (1993-1994), pp. 47-52.

WILLIAMS, David A. - Deformed discourse. The function of the Monster in Mediaeval Thought and Literature. Exeter: University of Exeter Press, 1996.

WITTKOWER, Rudolf - "Marvels of the East. A study in the history of monsters". Journal of the Warburg and Courtauld Institutes, vol. 5 (1942), pp. 159-197.

\section{COMO CITAR ESTE ARTIGO}

\section{Referência electrónica:}

CASTRO HERNÁNDEZ, Pablo - "Monstruos, prodigios y maravillas en los viajes de Pero Tafur”. Medievalista [Em linha]. N. 20, (Julho - Dezembro 2016). [Consultado dd.mm.aaaa]. Disponível em http://www2.fcsh.unl.pt/iem/medievalista/MEDIEVALISTA20/hernandez2006.html ISSN 1646-740X. 


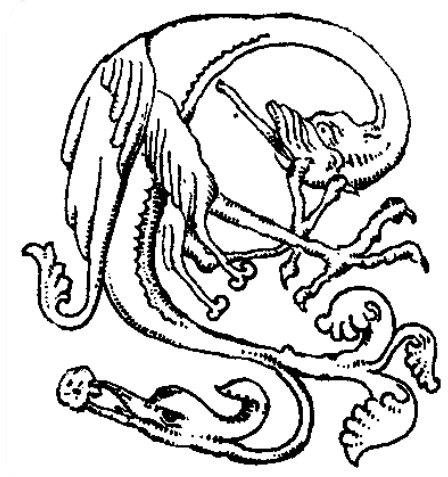

Medievalísta online $N^{\circ} 20$ | Julho - Dezembro 2016 ( IEM - Instituto de Estudos Medievais 25 www2.fcsh.unl.pt/iem/medievalista 